\title{
DDAH2 alleviates myocardial fibrosis in diabetic cardiomyopathy through activation of the DDAH/ADMA/NOS/NO pathway in rats
}

\author{
ZHEN-DONG ZHU ${ }^{1}$, JI-MING YE ${ }^{2}$, XUE-MEI FU ${ }^{3}$, XUE-CHANG WANG ${ }^{4}$, JI-YUN YE $^{5}$, \\ XIN-RAN WU ${ }^{6}$, PENG HUA ${ }^{4}$, YU-QIONG LIAO ${ }^{3}$, WEI XUAN $^{3}$, JIN-LAN DUAN $^{3}$, \\ WEI-YUAN $\mathrm{LI}^{3}$, $\mathrm{HUI} \mathrm{FU}^{7}$, ZHONG-HUA XIA ${ }^{8}$ and XUAN ZHANG ${ }^{9}$
}

${ }^{1}$ Yunnan Research Center for Geriatric Diseases; Departments of ${ }^{2}$ Pharmacy and ${ }^{3}$ Geriatrics, The First People's Hospital of Yunnan Province, Affiliated Hospital of Kunming Science and Technology University, Kunming, Yunnan 650032;

${ }^{4}$ Department of Pharmacy, the Third People's Hospital of Yunnan Province, The Second Affiliated Hospital of Dali University, Kunming, Yunnan 650011; ${ }^{5}$ Pathogenic Organisms Department of Experimental Center, School of Basic Medical Sciences, Kunming Medical University, Kunming, Yunnan 650500; ${ }^{6}$ Center Laboratory,

The Third People's Hospital of Yunnan Province, The Second Affiliated Hospital of Dali University, Kunming,

Yunnan 650011; ${ }^{7}$ Clinic Laboratory, The First People's Hospital of Yunnan Province, Affiliated Hospital of Kunming Science and Technology University, Kunming, Yunnan 650032; ${ }^{8}$ Clinical Medical College of Dali University, Dali, Yunnan 671003; ${ }^{9}$ School of Pharmaceutical Science and Yunnan Key Laboratory of Pharmacology for Natural Products, Kunming Medical University, Kunming, Yunnan 650500, P.R. China

Received July 19, 2018; Accepted November 27, 2018

DOI: $10.3892 / \mathrm{ijmm} .2018 .4034$

\begin{abstract}
Diabetic cardiomyopathy (DCM) is a form of idiopathic heart disease, with signs including hypertrophy of myocardial cells, hypertension-independent fibrosis and coronary artery disease. Considering the involvement of dimethylarginine dimethylaminohydrolase 2 (DDAH2) in diabetes, it was hypothesized that DDAH2 may be beneficial to cardiac function and myocardial fibrosis during the progression of DCM with involvement of the DDAH/asymmetric $\mathrm{N}^{\mathrm{G}}, \mathrm{N}^{\mathrm{G}}$ dimethyl-L-arginine (ADMA)/nitric oxide synthase (NOS)/nitric oxide (NO) signaling pathway. Following establishment of diabetic rat models, diabetes-related blood biochemical indices and cardiac function were measured in diabetic rats treated with lentivirus expressing DDAH2, short
\end{abstract}

Correspondence to: Dr Zhen-Dong Zhu, Yunnan Research Center for Geriatric Diseases, The First People's Hospital of Yunnan Province, Affiliated Hospital of Kunming Science and Technology University, 157 Jinbi Road, Xishan, Kunming, Yunnan 650032, P.R. China E-mail: zhuzhendong77@sina.com

Dr Xuan Zhang, School of Pharmaceutical Science and Yunnan Key Laboratory of Pharmacology for Natural Products, Kunming Medical University, 1168 West Chunrong Road, Yuhua Avenue, Chenggong, Kunming, Yunnan 650500, P.R. China

E-mail: drzhangxuan@163.com

Key words: diabetic cardiomyopathy, dimethylarginine dimethylaminohydrolase 2; dimethylarginine dimethylaminohydrolase/ asymmetric $\mathrm{N}^{\mathrm{G}}, \mathrm{N}^{\mathrm{G}}$ dimethyl-L-arginine/nitric oxide synthase/nitric oxide pathway, cardiac function, myocardial fibrosis hairpin RNA against DDAH2, or L-NNA (inhibitor of NOS) to identify the roles of DDAH2 in DCM. The functional roles of DDAH2 in DCM were further determined through detection of the levels of collagen I, matrix metalloproteinase 2 (MMP2) and tissue inhibitor of metalloproteinase 2 (TIMP2). The H9C2 myocardial cell line was selected for in vitro experiments. The effects of DDAH2 on the migration of myocardial cells under high glucose conditions were also examined. To further investigate the underlying regulatory mechanism of DDAH2 in DCM, the contents of ADMA and NO, and the activities of DDAH and NOS were observed. The DCM model rats treated with DDAH2 exhibited reduced left ventricular end-diastolic pressure, and decreased blood glucose, total cholesterol, triglyceride, fasting blood glucose, and fasting insulin levels, but exhibited increased left ventricular systolic pressure and maximum rate of left ventricular pressure rise/fall levels in myocardial tissues. Myocardial cells under high glucose conditions treated with DDAH2 showed reductions in collagen I, MMP2 and TIMP2, indicating that DDAH2 reduced cell migration. Decreased levels of ADMA and NO but increased levels of DDAH and NOS were observed following treatment with DDAH2, indicating that the DDAH/ADMA/NOS/NO pathway was activated. These results reveal that the overexpression of DDAH2 attenuates myocardial fibrosis and protects against DCM through activation of the DDAH/ADMA/NOS/NO pathway in DCM rats. These results indicate that DDAH2 is a potential therapeutic candidate for the treatment of DCM.

\section{Introduction}

In Asia, diabetes is a common and disease with an increasing prevalence rate estimated (1). Diabetes has become 
increasingly widespread and is now recognized as an epidemic disease in China which is specifically analyzed (2-4). Diabetic cardiomyopathy (DCM) is recognized as a primary complication and the main cause of morbidity and mortality in diabetic patients, who have a 2-5-fold increased risk of developing heart failure, reduced forced vital capacity and forced expiratory volume/sec when compared with non-diabetic individuals $(5,6)$. Myocardial fibrosis, known as a pathological entity of extracellular matrix remodeling, often induces myocardial stiffness and exaggerates cardiac dysfunction (7). Myocardial fibrosis and cardiac function are vital indicators of diabetes, and have been analyzed and investigated previously (8-10). Treatment against fibrosis with the early utilization of angiotensin-converting enzyme inhibitors may be a potential diabetic strategy (11). Dimethylarginine dimethylaminohydrolase (DDAH) dysregulation has been found to exert notable effect during the progression of diabetic nephropathy through elevating asymmetric dimethylarginine levels (12). Therefore, the present study investigated the role of DDAH2 under experimental diabetic conditions to test the hypothesis that DDAH2 dysregulation is involved in the progression of fibrosis in DCM.

DDAH is an enzyme which can metabolize competitive endogenous inhibitors of nitric oxide (NO) synthase (NOS), including asymmetric $\mathrm{N}^{\mathrm{G}}$, $\mathrm{N}^{\mathrm{G}}$ dimethyl-L-arginine (ADMA) and $\mathrm{N}^{\mathrm{G}}$-monomethyl-L-arginine (13). DDAH consists of two isoforms, namely DDAH1 and DDAH2 in mammals, which are expressed in the cardiovascular system (14). Of note, the expression of DDAH2 was shown to be noticeably downregulated in the adipose tissue of diabetic rats (15). Diabetic endothelial dysfunction may arise from the uncoupling of endothelial nitric oxide synthase (eNOS) by forming superoxide anion $[\mathrm{O}(2)(-)](16)$. ADMA, a naturally existing L-arginine analog endogenously synthesized during the methylation of protein arginine residues, is an inhibitor of NOS by competing with L-arginine to bind to the active site of NOS, thus suppressing NO synthesis and causing NOS uncoupling (17). The majority of ADMA can be intracellularly degraded into citrulline and dimethylamine by DDAH (18). A previous study revealed that the level of exogenous ADMA increased, whereas the overexpression of DDAH2 suppressed the senescence of high glucose-induced endothelial progenitor cells (19). In addition, the activity of DDAH is involved in endothelial dysfunction in diabetes, indicating that preservation of the activity of DDAH in vessels and the reduction of endogenous ADMA may underlie the protective mechanism alleviating the impairment of endothelium-dependent vasodilatation (20). In this regard, the expression of DDAH2 was associated with endothelial dysfunction in diabetic rats or cell damage in a high glucose environment $(19,20)$. Considering the role of DDAH2 in diabetes, the present study hypothesized that DDAH2 may be implicated in DCM through involvement of the DDAH/ADMA/NOS/NO pathway. The present study was performed to examine whether DDAH2 is a novel target for improving the clinical outcome of DCM by ameliorating cardiac function and myocardial fibrosis via the DDAH/ADMA/NOS/NO pathway.

\section{Materials and methods}

Ethical statement. The animal experiments were approved by The First People's Hospital of Yunnan Province, Affiliated
Hospital of Kunming Science and Technology University (Kunming, China). Efforts were made to minimize the suffering of animals. All experimental procedures and protocols were in line with the recommendations of the Guide for the Care and Use of Laboratory Animals of the American National Institutes of Health.

Animal treatment. A total of 100 Wistar male rats (weighing 190-200 g; aged 6 weeks) were purchased from the Laboratory Animal Center, Kunming Medical University (Kunming, China) for the following in vivo experiments. Streptozotocin (STZ) (Sigma-Aldrich; Merck KGaA, Darmstadt, Germany) injection was used for diabetic rat model establishment. STZ was dissolved in $0.1 \mathrm{mmol} / \mathrm{l}$ citric acid buffer ( $\mathrm{pH} 4.5$ ) to prepare $1 \%$ STZ solution. The rats were intraperitoneally injected with STZ solution $(30 \mathrm{mg} / \mathrm{kg}$ ). After $72 \mathrm{~h}$, venous blood from the rat tails was collected, with blood glucose (BG) $\geq 16.7 \mathrm{mmol} / 1$ considered successful model establishment. The rate of successful modeling was $83 \%(83 / 100)$. Of the 100 rats, 10 died and seven rats were unsuccessfully modeled with $\mathrm{BG}<16.7 \mathrm{mmol} / \mathrm{l}$. The rats successfully modeled were randomly grouped into a model group, DDAH2 group, DDAH2-NC group, short hairpin RNA (sh)DDAH2 group, shDDAH2-NC group, L-NNA group and L-NNA + DDAH2 group, with 10 animals in each group. Subsequently, $2.5 \times 10^{10} \mathrm{PFU} / \mathrm{ml}$ DDAH2 lentivirus ( $\mu \mathrm{l}$ ), DDAH2-NC lentivirus, shDDAH2 lentivirus $(2 \mu \mathrm{l})$, shDDAH2-NC lentivirus ( $2 \mu \mathrm{l})$ and shDDAH2-NC lentivirus $(2 \mu \mathrm{l})$ were injected in the tail vein of the rats in the DDAH2 group, the DDAH2-NC group, the shDDAH2 group, the shDDAH2-NC group, and the L-NNA+DDAH2 group respectively. All lentivirus vectors were produced by Beijing Nuosai Biotechnology Co., Ltd. (Beijing, China). After 1 week, the injection was repeated again. Meanwhile, the NOS inhibitor L-NNA $(5 \mathrm{mg} / \mathrm{kg})$ was intraperitoneally injected into the rats of the L-NNA and L-NNA + DDAH2 groups following establishment of the rat models. The same dose of NOS inhibitor L-NNA was injected again after $20 \mathrm{~h}$. The rats were housed at room temperature with a relative humidity of $50-60 \%$, free access to food and water, and a 12-h light/dark cycle.

Cell grouping and culture. The $\mathrm{H} 9 \mathrm{C} 2$ primary rat myocardial cell line (Institute of Biochemistry and Cell Biology, Shanghai Institutes for Biological Sciences, Chinese Academy of Sciences, Shanghai, China) was used for in vitro experiments. The cells were assigned into the model group $(\mathrm{H} 9 \mathrm{C} 2$ cells treated with high glucose), DDAH2 group (H9C2 cells treated with high glucose and transfected with DDAH2 plasmid), DDAH2-NC group (H9C2 cells treated with high glucose and transfected with DDAH2-NC plasmid), shDDAH2 group (H9C2 cells treated with high glucose and transfected with shDDAH2 plasmid), shDDAH2-NC group (H9C2 cells treated with high glucose and transfected with shDDAH2-NC plasmid), L-NNA group ( $\mathrm{H} 9 \mathrm{C} 2$ cells treated with high glucose and incubated with $50 \mu \mathrm{mol} / 1 \mathrm{~L}-\mathrm{NNA}$ for $48 \mathrm{~h}$ ) and L-NNA + DDAH2 group (H9C2 cells treated with high glucose, incubated with $50 \mu \mathrm{mol} / 1 \mathrm{NOS}$ inhibitor L-NNA for $48 \mathrm{~h}$ and transfected with DDAH2 plasmid). The cells were cultured in Dulbecco's modified Eagle's medium containing 10\% fetal bovine serum (FBS) (all purchased from Sigma-Aldrich; Merck KGaA) $1 \times 10^{5} \mathrm{U} / 1$ 
penicillin, and $100 \mathrm{mg} / \mathrm{l}$ streptomycin at $37^{\circ} \mathrm{C}$ with $5 \% \mathrm{CO}_{2}$. The medium was changed every 2 days. The cells were subcultured when cell confluence reached $80-90 \%$. The cells prepared for high glucose treatment were cultured in culture medium with $30 \mathrm{ml} / \mathrm{l}$ glucose, and cells at the exponential growth phase were used for subsequent experiments.

Construction and transfection of plasmid. According to the known DDAH2 sequence in NCBI (https://www.ncbi. nlm.nih.gov/nuccore/NM_212532.2), the DDAH2 plasmid, DDAH2-NC plasmid, shDDAH2 plasmid, and shDDAH2-NC plasmid were constructed by Sangon Biotech Co., Ltd., (Shanghai, China). At the same time, three different plasmids were screened to avoid off-target effects.

The third generation cells were detached by trypsin and inoculated into a 24-well plate for the cells to grow into monolayers with medium discarded. Transfection was performed using Lipofectamine 2000 (Invitrogen; Thermo Fisher Scientific, Inc., Waltham, MA, USA) according to the manufacturer's protocol. The procedure was as follows: H9C2 cells were seeded into a 6 -well plate at a density of $2 \times 10^{5}$ cells/well and, when the cells had adhered to the wall, the medium was replaced with culture medium without penicillin/streptomycin $12 \mathrm{~h}$ prior to transfection. Subsequently, $100 \mu \mathrm{l}$ liposome was diluted in $250 \mu \mathrm{l}$ OPTI-MEM medium, triturated with a pipette and mixed prior to incubation at room temperature for $5 \mathrm{~min}$. The plasmid vectors $(4 \mu \mathrm{g})$ were diluted in $250 \mu \mathrm{l}$ OPTI-MEM, triturated with a pipette and mixed prior to incubation at room temperature for $20 \mathrm{~min}$, and then added to a 6-well plate containing $1.5 \mathrm{ml}$ OPTI-MEM and mixed. The cells were incubated in a $5 \% \mathrm{CO}_{2}$ incubator at $37^{\circ} \mathrm{C}$, and the medium was replaced with complete medium at $6 \mathrm{~h}$. To screen out the stably transfected cells at $48 \mathrm{~h}$ post-transfection, the cells were seeded into G418 (1,000-2,000 $\mu \mathrm{g} / \mathrm{ml})$ medium for 4 weeks and the medium was replaced every 3-5 days.

Assessment of cardiac function in rats. Following lentivirus injection for 12 weeks, five rats in each group were heparinized by injection of $0.3 \%$ heparin $(2 \mathrm{mg} / \mathrm{kg})$ into the tail vein, intraperitoneally injected with $3 \%$ sodium pentobarbital $(40 \mathrm{mg} / \mathrm{kg}$ ) and anesthetized. Following fixation, the right common carotid artery of the rats was bluntly separated via a cervical median incision with the arteries ligated at the distal end of the heart. Subsequently, the proximal end of the heart was clamped and a small opening was cut in the artery wall to insert a catheter connected to the pressure transducer (Miller, Houston, TX, USA). The catheter was then placed into the left ventricle for several minutes with the ligature released. The catheter was connected to the Power Lab biometrics experiment system channel (AD Instruments, Oxford, UK) via a pressure transducer to measure the left ventricular end-diastolic pressure (LVEDP), left ventricular systolic pressure (LVSP), and the maximum rate of left ventricular pressure rise/fall $(\mathrm{LV} \pm \mathrm{dp} / \mathrm{dt})$.

Blood biochemical assessment. The BG was measured in five rats selected from each group using the glucose oxidase method at $0,5,15$ and 20 weeks. The steps of the glucose oxidase method were as follows: $10 \mu 1$ plasma was added to $1.5 \mathrm{ml}$ enzyme-buffer working solution, mixed and placed in a $37^{\circ} \mathrm{C}$ water bath for $10 \mathrm{~min}$. A microplate reader (MK3, Thermo Fisher Scientific, Inc.) was used for assessment of the optical density (OD) values at $500 \mathrm{~nm}$. The glucose levels were calculated according to formulas. The levels of total cholesterol (TC), triglyceride (TG) and fasting blood glucose (FBG) in the rats were analyzed using the Bayer 1650 blood chemistry analyzer (Bayer AG, Leverkusen, Germany). An enzyme-linked immunosorbent assay was used to detect the fasting insulin (FINS) levels of the rats in each group.

Masson staining. Following the analysis of blood biochemistry, the five rats in each group were sacrificed, limbs were fixed, the chest was opened in a sterile environment and the heart was removed. The heart was gently washed in phosphate-buffered saline (PBS) and then the residual blood in heart was extruded. The heart was trimmed and myocardial tissue samples of each group were obtained. The myocardial tissues were used for Masson staining and hematoxylin and eosin (H\&E) staining, DDAH activity detection, reverse transcription-quantitative polymerase chain reaction (RT-qPCR) analysis and western blot analysis.

The myocardial tissues were fixed with $4 \%$ paraformaldehyde, embedded with paraffin, and cut into sections with a thickness of $4-\mu \mathrm{m}$. Following dewaxing, the tissue sections were stained with hematoxylin for $5 \mathrm{~min}$, differentiated with hydrochloric acid ethanol, and then stained with Masson ponceau acid fuchsin solution for $5 \mathrm{~min}$. Following rapid washing under water, the sample sections were stained with $1 \%$ phosphomolybdic acid for $3 \mathrm{~min}$ and stained with toluidine blue for $5 \mathrm{~min}$ prior to drying. Following this, the sections were mounted with gum and observed under a microscope (Nikon Ecliose 80i, Nikon Corporation, Tokyo, Japan).

$H \& E$ staining. The paraffin sections in each group were dewaxed and stained with hematoxylin for $5 \mathrm{~min}$, followed by differentiation with ethanolic hydrochloric acid. The paraffin sections were washed and stained with eosin for $2 \mathrm{~min}$. The sample sections were then quickly washed with water, dried, mounted with gum and observed under the microscope (Nikon Eclipse 80i, Nikon Corporation).

Transwell assay. Following transfection for $24 \mathrm{~h}$, the cells in each group were detached with trypsin and resuspended in serum-free medium containing bovine serum albumin (Sigma-Aldrich; Merck KGaA) for preparation of the cell suspension. Subsequently, $200 \mu 1$ cell suspension was added to an 8-mm Transwell chamber (Costar, High Wycombe, UK) and placed in a 24-well plate. A total of $500 \mu 1$ medium containing $20 \%$ FBS was added to the basolateral chamber for incubation for $24 \mathrm{~h}$ at $37^{\circ} \mathrm{C}$ with $5 \% \mathrm{CO}_{2}$. Cells in the apical chamber were wiped off with a cotton swab, washed with PBS 3-5 times, fixed with methanol for $20 \mathrm{~min}$, and stained with $0.1 \%$ crystal violet for $20 \mathrm{~min}$. Under an inverted microscope (Olympus, Corporation, Tokyo, Japan), five visual fields were randomly selected and images were captured. The experiment was repeated three times with the mean value obtained.

Measurement of ADMA concentration, activity of DDAH in myocardial tissue, activity of NOS and NO content in 
serum. The ADMA concentration was determined by high performance liquid chromatography. Five rats were selected from each group, and $1 \mathrm{ml}$ serum from the rat was added to 5 -sulfosalicylic acid precipitation protein at $4^{\circ} \mathrm{C}$ and centrifuged at $2,000 \mathrm{xg}$ for $5 \mathrm{~min}$ at $4^{\circ} \mathrm{C}$. Following that, $10 \mu 1$ serum or standard samples were added to $100 \mu 1$ derivatization reagent (mixture of phthalaldehyde, borate buffer and D-mercaptoethanol), triturated with pipette fully, mixed and placed at room temperature for $3 \mathrm{~min}$. The samples were then eluted using a linear gradient (mobile phase: $4 \%$ acetonitrile and $0.4 \%$ trifluoroacetic acid; flow rate: $0.2 \mathrm{ml} / \mathrm{min}$ ). ADMA was then separated on columns in samples and internal standard samples, prior to being determined using a mass spectrometer (MS-2010; ADMAM/Z: 203, N2 flow rate: $4.0 \mathrm{l} / \mathrm{min}$ ). Subsequently, the cells in each group were detached with $0.25 \%$ trypsin and centrifuged at $1,000 \mathrm{x} \mathrm{g}$ for $5 \mathrm{~min}$ at $4^{\circ} \mathrm{C}$ with the supernatant discarded. The cells were resuspended with $1 \mathrm{ml}$ ice phosphate buffer (pH 6.5, $0.1 \mathrm{~mol} / \mathrm{l}$ ), split by sonication, and then centrifuged at $3,500 \times \mathrm{g}$ for $30 \mathrm{~min}$ at $4^{\circ} \mathrm{C}$. Subsequently, the ADMA concentration in $50 \mu \mathrm{l}$ of supernatant was measured as described above.

The activity of DDAH in myocardial tissues was determined as follows: $0.1 \mathrm{mmol} / \mathrm{l} \mathrm{L}$-proline $(500 \mu \mathrm{l})$ were taken from a standard tube, and $50 \mu \mathrm{l}$ myocardial homogenate and $50 \mu 1$ cell lysate were taken from a testing tube and a control tube respectively. Subsequently, $100 \mu 1$ ADMA standard solution $(1 \mathrm{mmol} / \mathrm{l})$ was added into the testing tube and an equal volume of PBS was added into the control tube and placed at room temperature for $2 \mathrm{~h}$. To each tube, $10 \%$ trichloroacetic acid $(0.5 \mathrm{ml})$ was added and centrifuged at $1,000 \mathrm{x} \mathrm{g}$ for $10 \mathrm{~min}$ at $4^{\circ} \mathrm{C}$. Following the addition of $0.5 \mathrm{ml}$ of supernatant into a clean glass test tube, $0.5 \mathrm{ml}$ $\mathrm{ddH}_{2} \mathrm{O}, 1 \mathrm{ml}$ colorimetric solution containing $0.8 \%$ diacetyl monohydrazine and $0.5 \%$ antipyrine at the ratio of $2: 1$ were added, prior to sealing with preservative film. The tubes were placed in a water bath at $60^{\circ} \mathrm{C}$ for $100 \mathrm{~min}$ and cooled in ice water for several seconds without exposure to light, following which the OD value at $466 \mathrm{~nm}$ of each tube was determined with a full-wavelength UV spectrophotometer. The enzymatic activity of DDAH was the quantity of DDAH required to form $1 \mu \mathrm{mol} / 1 \mathrm{~L}$-proline per min at $37^{\circ} \mathrm{C}$ (expressed as $\mathrm{U} / \mathrm{g}$ protein).

A NOS activity assay kit (Nanjing Jiancheng Biotechnology Co., Ltd., Nanjing, China) was used to measure NOS activity. The procedure was as follows: $50 \mu \mathrm{l}$ supernatant or cell lysate of myocardial tissues following homogenization and centrifugation was added into a testing tube, and $50 \mu 1 \mathrm{ddH}_{2} \mathrm{O}$ was added into a control tube. In each tube, $200 \mu 1$ substrate buffer, $10 \mu 1$ accelerant and $100 \mu \mathrm{l}$ color reagent were added, mixed and incubated for $15 \mathrm{~min}$ at $37^{\circ} \mathrm{C}$. Following the addition of $100 \mu \mathrm{l}$ clear reagent and $2 \mathrm{ml}$ stop solution, the tissues were mixed and placed under plate reader (MK3, Thermo Fisher Scientific, Inc.) for assessment of the OD value at $530 \mathrm{~nm}$. The NOS activity in each group was calculated according to following formulae: NOS activity $=\left(\mathrm{OD}_{\text {testing tube }}-\mathrm{OD}_{\text {control tube }}\right) /$ molar extinction coefficient $x$ (the total volume of reaction liquid/the volume of sample) $\mathrm{x}(1 /$ the time of reaction/the diameter of colorimetric ware)/the content of protein.
A NO content assay kit (Nanjing Jiancheng Biotechnology Co., Ltd., Nanjing, China) was used to determine the NO content. The procedures were as follows: $0.5 \mathrm{ml}$ supernatant or cell lysate of myocardial tissues following homogenization and centrifugation was added into a testing tube,

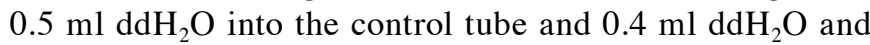
$0.1 \mathrm{ml} 10 \mu \mathrm{mol} / 1$ standard liquid into the standard tube. Subsequently, $0.4 \mathrm{ml}$ Reagent One and $0.4 \mathrm{ml}$ Reagent Two were added into each tube and mixed fully with vortex and placed in a water bath at $37^{\circ} \mathrm{C}$ for $60 \mathrm{~min}$. Subsequently, $0.2 \mathrm{ml}$ Reagent Three and $0.1 \mathrm{ml}$ Reagent Four were mixed fully for $30 \mathrm{sec}$, and allowed to stand for $40 \mathrm{~min}$ at room temperature. Following centrifugation at $3,500 \mathrm{x} \mathrm{g}$ for $10 \mathrm{~min}$ at $4^{\circ} \mathrm{C}, 0.8 \mathrm{ml}$ supernatant and $0.6 \mathrm{ml}$ color reagent were added, mixed thoroughly with a vortex and allowed to stand for $10 \mathrm{~min}$. The OD values of the culture medium at $550 \mathrm{~nm}$ were measured using a microplate reader (MK3, Thermo Fisher Scientific, Inc.). The NO content in each group was calculated according to formulas: NO content $\left({ }_{\mu \mathrm{mol} / \text { gprot }}\right)=\left(\mathrm{OD}_{\text {testing tube }}-\mathrm{OD}_{\text {control tube }}\right) /\left(\mathrm{OD}_{\text {standard tube }}-\mathrm{OD}_{\text {control }}\right.$ tube) $\mathrm{x}$ concentration ${ }_{\text {standard liquid }(20 \mu \mathrm{mol} / \mathrm{l} / \mathrm{f}} /$ protein concentration testing sample (gprot/l)

$R T-q P C R$ analysis. Total RNA was extracted from the tissues and cells in each group using TRIzol Reagent (Takara Biotechnology, Co., Ltd., Dalian, China) with the RNA purity and concentration measured using a NanoDrop ND-1000 spectrophotometer (NanoDrop Technologies, Inc. Rockland, DE, USA). Subsequently, the PrimeScript RT reagent kit (Takara Biotechnology Co., Ltd.) was used for RT of the RNA into cDNA. The reaction system was as follows: $0.5 \mu 1$ PrimeScript RT Enzyme mix, $4 \mu 1$ 5X PrimeScript buffer, $1 \mu \mathrm{l}$ RT primer, total RNA of $500 \mathrm{ng}$, with RNase Free $\mathrm{ddH}_{2} \mathrm{O}$ added to a total PCR volume of $20 \mu \mathrm{l}$. The reaction conditions were as follows: At $37^{\circ} \mathrm{C}$ for $15 \mathrm{~min}$ and at $85^{\circ} \mathrm{C}$ for $5 \mathrm{sec}$. A UV spectrophotometer and $1 \%$ agarose gel were used to measure DNA concentration and purity (A260/A280 >1.8).

The prepared cDNA was subjected to the following experiments using the SYBR Premix Ex Taq II kit (Takara Bio, Inc., Tokyo, Japan) with glyceraldehyde-3-phosphate dehydrogenase (GAPDH) used as an internal reference. The reaction conditions were as follows: Pre-denaturation at $94^{\circ} \mathrm{C}$ for $10 \mathrm{~min}, 25$ cycles of denaturation at $94^{\circ} \mathrm{C}$ for $1 \mathrm{~min}$, annealing at $60^{\circ} \mathrm{C}$ for $45 \mathrm{sec}$ and extension at $72^{\circ} \mathrm{C}$ for $2 \mathrm{~min}$. The reaction system was as follows: $1 \mu \mathrm{l}$ template cDNA, $0.4 \mu \mathrm{l}$ forward primers and $0.4 \mu \mathrm{l}$ reverse primers, $10 \mu 1$ SYBR Premix Ex Taq, and $0.4 \mu 1$ of ROX (50X), with $\mathrm{ddH}_{2} \mathrm{O}$ added to a total PCR volume of $20 \mu \mathrm{l}$. The primers used are shown in Table I. All RT-qPCR experiments were performed using an ABI7500 quantitative PCR instrument (Applied Biosystems; Thermo Fisher Scientific, Inc.). The dissolution curves at $60-90^{\circ} \mathrm{C}$ were drawn to ensure that single products were amplified and the $\mathrm{Cq}$ value was used. The $2^{-\Delta \Delta C q}$ method (21) was applied to detect the relative expression of each gene.

Western blot analysis. A total of $20 \mathrm{mg}$ myocardial tissues from the rats in each group were supplemented with pre-cooled $2 \%$ sodium dodecyl sulfate at ratio of 1:20 (m:V), homogenized on ice for $10 \mathrm{sec}$ in an electric homogenizer, and 
Table I.Primer sequences for reverse transcription-quantitative polymerase chain reaction analysis.

\begin{tabular}{ll}
\hline Gene & \multicolumn{1}{c}{ Sequence (5'-3') } \\
\hline PRMT1 & F: AACCCTCACGTACCGCAACTCC \\
& R: CAGCCACTTGTCACGAGCGT \\
DDAH2 & F: GCAACGACTAGGTCTGCAGCTTC \\
& R: GGTACCGTAGAGACAGCGAAGTC \\
DDAH1 & F:AGCCGCAGGAAGGAGGTTGACATGAT \\
& R: GGTACTCTTCTGGGGTTGGGTGCA \\
Collagen I & F: TTCACCTACTGCACGCTTGT \\
& R: TTGGGATGGAGGGAGTTTAC \\
MMP2 & F: GATACCCTCAAGAAGATGCAGAAGT \\
& R: ATCTTGGCTTCCGCATGGT \\
TIMP2 & F: GGCAAGATGCACATTACC \\
& R: AACTTGGCATTGTGGAAGG \\
GAPDH & F: GTCTTCACTACCATGGAGAAG \\
& R: TCATGGATGACCTTGGCCAG
\end{tabular}

PRMT1, protein arginine N-methyltransferase 1; DDAH2, dimethylarginine dimethylaminohydrolase 2; DDAH1, dimethylarginine dimethylaminohydrolase 1; MMP2, matrix metalloproteinase 2; TIMP2, tissue inhibitor of metalloproteinase 2; GAPDH, glyceraldehyde-3-phosphate dehydrogenase; F, forward; R, reverse.

boiled at $100^{\circ} \mathrm{C}$ for $5 \mathrm{~min}$. Following cooling, the tissues were centrifuged at $12,000 \times \mathrm{g}$ for $4 \mathrm{~min}$ at $4^{\circ}$, and the supernatant was collected as tissue protein samples. In each group, cells at the exponential growth phase were harvested following $72 \mathrm{~h}$ of culture, and total protein was extracted using the NucBusterä Protein Extraction kit (Novagen, Madison, WI, USA).

The concentration of protein samples was determined using a bicinchoninic acid kit (Pierce; Thermo Fisher Scientific, Inc.) with $30 \mu \mathrm{g}$ protein sample in each protein lane adjusted by deionized water. Subsequently, the 10\% SDS separation gel and spacer gel were prepared, and the samples were mixed with sample buffer prior to being boiled at $100^{\circ} \mathrm{C}$ for $5 \mathrm{~min}$. After cooling to room temperature, each sample was subjected to electrophoresis by adding micro sampler into lanes. Subsequently, the protein on the gel was transferred onto a polyvinylidene fluoride membrane, which was then blocked with $5 \%$ skim milk overnight at $4^{\circ} \mathrm{C}$. The membrane was incubated with the following diluted primary antibodies at $4^{\circ} \mathrm{C}$ overnight: Rabbit anti-rat protein arginine N-methyltransferase 1 (PRMT1; 1:1,000; cat. no. ab73246), rabbit anti-rat DDAH2 (1:500; cat. no. ab1383), rabbit anti-rat DDAH1 (1:500; cat. no ab2231), rabbit anti-rat collagen I (1:1,000; cat. no. ab34710), rabbit anti-rat matrix metalloproteinase 2 (MMP2; 1:2,000, cat no. ab37150) and rabbit anti-rat tissue inhibitor of metalloproteinase 2 (TIMP2; 1:500; cat. no. ab180630). This was followed by three PBS washes ( 5 min each time) at room temperature. All the above antibodies were purchased form Abcam (Cambridge, MA, USA). Subsequently, the membrane was incubated with secondary antibody, horseradish peroxidase-labeled goat anti-rabbit IgG (1:3,000; cat. no. ab6721, Abcam) at $37^{\circ} \mathrm{C}$ for $1 \mathrm{~h}$, followed by three PBS washes (5 min each time). The membrane was then immersed in electroluminescence reaction liquid (Pierce; Thermo Fisher Scientific, Inc.) for $1 \mathrm{~min}$ at room temperature and the liquid aspirated, followed by covering with preservative film and observing under a chemiluminometer (Shanghai Tianneng Co., Ltd., Shanghai, China) with GAPDH (1: 2,500; cat. no. ab9485' Abcam) as an internal reference. Finally, the ratio of the gray value of the target protein band/GAPDH protein band was considered the relative protein expression.

Statistical analysis. SPSS 21.0 (IBM Corp., Armonk, NY, USA) was used for statistical analysis. All experimental results were examined for Gaussian distribution and homogeneity of variance. Continuous variables are expressed as the mean \pm standard deviation in the case of Gaussian distribution and as median (interquartile range) in the case of variables with non-normal distribution. Comparison of measurement data among multiple groups was performed using one-way analysis of variance, and post-hoc testing was conducted by Tukey's test. In addition, repeated-measures analysis of variance was used to compare data at different time points. $\mathrm{P}<0.05$ was considered to indicate a statistically significant difference.

\section{Results}

DDAH2 improves cardiac function in diabetic rats. The cardiac function was determined to examine the effect of DDAH2 on cardiac function in diabetic rats with myocardial fibrosis (Fig. 1A-D). Compared with the diabetic rats of the model group, a significant reduction in LVEDP was found in the diabetic rats of the DDAH2 group, whereas the levels of LVSP and LV $\pm \mathrm{dp} / \mathrm{dt}$ were increased (all $\mathrm{P}<0.05$ ). By contrast, the level of LVEDP increased significantly and notable decreases in the levels of LVSP and LV $\pm \mathrm{dp} / \mathrm{dt}$ were observed in the diabetic rats of the shDDAH2 and L-NNA groups (all $\mathrm{P}<0.05)$. No notable differences in LVEDP, $L V S P$ or $L V \pm \mathrm{dp} / \mathrm{dt}$ were observed in the diabetic rats of the model, DDAH2-NC, shDDAH2-NC and L-NNA + DDAH2 groups $(\mathrm{P}>0.05)$. Taken together, DDAH2 exhibited a protective effect on the cardiac function of diabetic rats with myocardial fibrosis.

DDAH2 decreases levels of biochemical indicators in diabetic rats. The levels of biochemical indicators were detected for determination of the role of DDAH2 in diabetic rats with myocardial fibrosis (Fig. 2A-E). From week 5 following treatment, the levels of BG, TC, TG, FBG and FINS in the rats of the DDAH2 group were lower than those in the diabetic rats of the model group $(\mathrm{P}<0.05)$, whereas the levels of BG, TC, TG, FBG, and FINS were increased in the diabetic rats of the shDDAH2 and L-NNA groups $(\mathrm{P}<0.05)$. No significant differences in BG, TC, TG, FBG or FINS were found in the diabetic rats of the model, DDAH2-NC, shDDAH2-NC and L-NNA + DDAH2 groups $(\mathrm{P}>0.05)$. Taking these results into consideration, the positive role of DDAH2 was identified as it alleviated myocardial fibrosis in diabetic rats.

DDAH2 attenuates myocardial fibrosis in diabetic rats. Masson staining and $H \& E$ staining were performed to further 

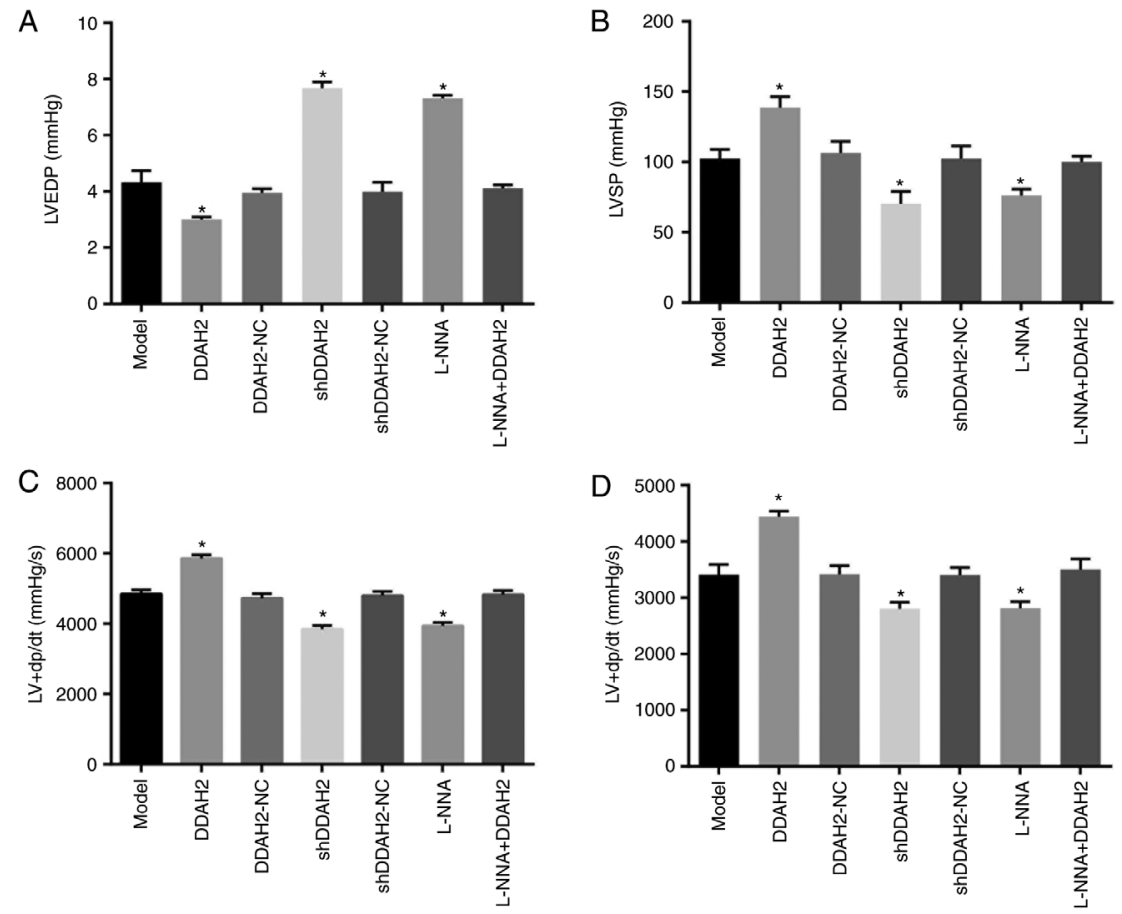

Figure 1. DDAH2 exerts a protective effect on cardiac function in diabetic rats with myocardial fibrosis. (A) LVEDP level in diabetic rats following 12 weeks of treatment with lentivirus expressing DDAH2 or shDDAH2, and/or L-NNA. (B) LVSP level in diabetic rats following 12 weeks of treatment with lentivirus expressing DDAH2 or shDDAH2, and/or L-NNA. (C) LV + dp/dt level in diabetic rats following 12 weeks of treatment with lentivirus expressing DDAH2 or shDDAH2, and/or L-NNA. (D) LV-dp/dt level in diabetic rats following 12 weeks of treatment with lentivirus expressing DDAH2 or shDDAH2, and/or L-NNA. Data are presented as the mean \pm standard deviation and analyzed by the one-way analysis of variance. All data are representative of three independent experiments. $n=5$. ${ }^{*} \mathrm{P}<0.05$, vs. model group. DDAH2, dimethylarginine dimethylaminohydrolase 2; NC, negative control; sh, short hairpin RNA; LVEDP, left ventricular end-diastolic pressure, LVSP, left ventricular systolic pressure, $L V \pm \mathrm{dp} / \mathrm{dt}$, maximum rate of left ventricular pressure rise/fall.
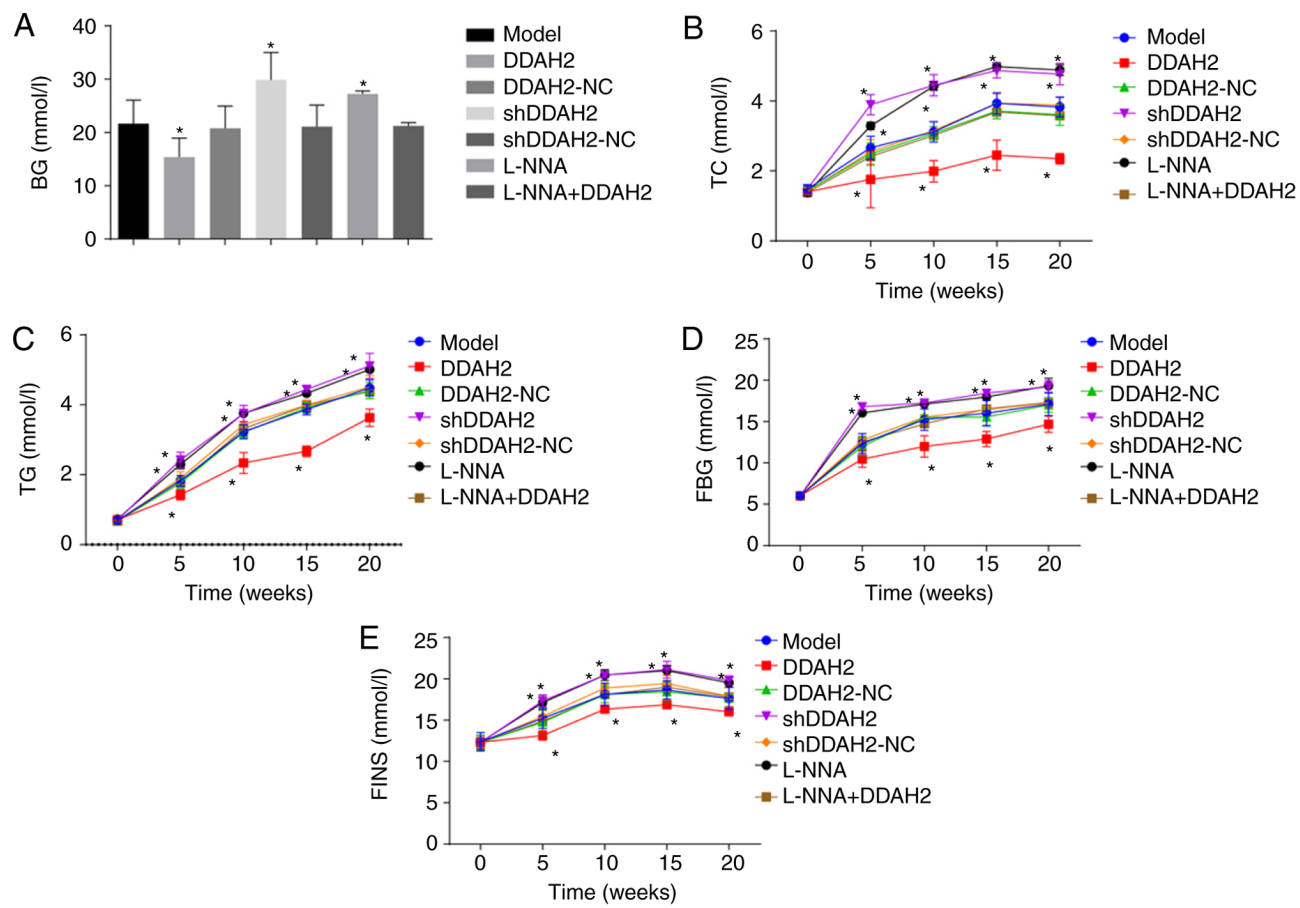

Figure 2. DDAH2 positively regulates blood biochemical indicators in diabetic rats with myocardial fibrosis. (A) BG level in diabetic rats following 5-20 weeks of treatment with lentivirus expressing DDAH2 or shDDAH2, and/or L-NNA. (B) TC level in diabetic rats following 5-20 weeks of treatment with lentivirus expressing DDAH2 or shDDAH2, and/or L-NNA. (C) TG level in diabetic rats following 5-20 weeks of treatment with lentivirus expressing DDAH2 or shDDAH2, and/or L-NNA. (D) FBG level in diabetic rats following 5-20 weeks of treatment with lentivirus expressing DDAH2 or shDDAH2, and/or L-NNA. (E) FINS in diabetic rats following 5-20 weeks of treatment with lentivirus expressing DDAH2 or shDDAH2, and/or L-NNA. "P $<0.05$. vs. model group. Data are presented as the mean \pm standard deviation; data at the same time point in different groups were analyzed by one-way ANOVA; data at different time points were analyzed by repeated measure ANOVA. All data are representative of three independent experiments. n=5. DDAH2, dimethylarginine dimethylaminohydrolase 2; NC, negative control; sh, sort hairpin RNA; BG, blood glucose; TC, total cholesterol; TG, triglyceride; FBG, fasting blood glucose; FINS, fasting insulin; ANOVA, analysis of variance. 

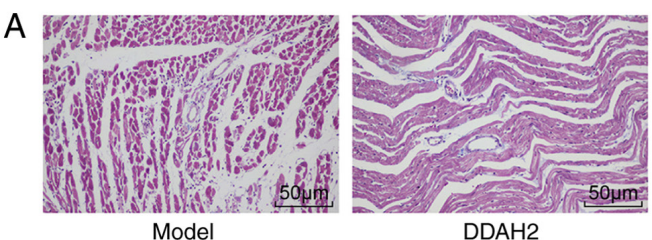

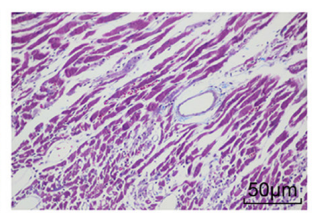

DDAH2-NC

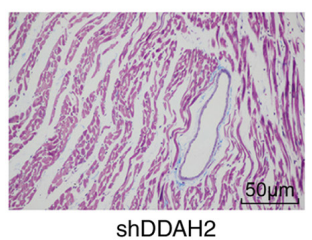

shDDAH2

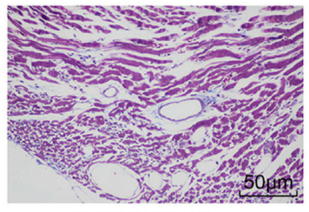

ShDDAH2-NC
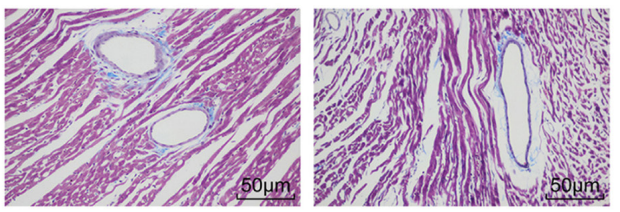

L-NNA+DDAH2
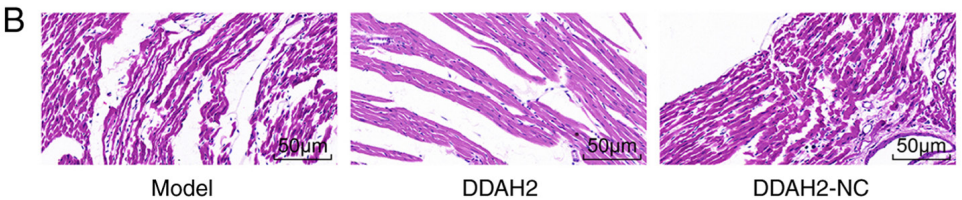

DDAH2-NC
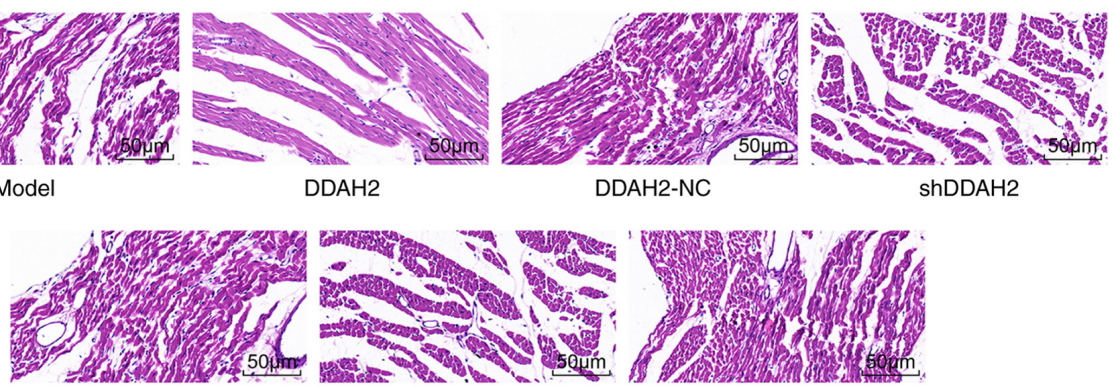

shDDAH2-NC
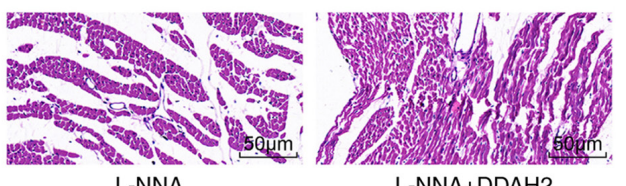

L-NNA+DDAH2

Figure 3. DDAH2 improves myocardial fibrosis in diabetic rats. (A) Masson staining results of diabetic rats following 20 weeks of treatment with lentivirus expressing DDAH2 or shDDAH2, and/or L-NNA in each group (magnification, $\mathrm{x} 400$ ). (B) hematoxylin and eosin staining results of diabetic rats following 20 weeks of treatment with lentivirus expressing DDAH2 or shDDAH2, and/or L-NNA in each group (magnification, x200). DDAH2, dimethylarginine dimethylaminohydrolase 2; NC, negative control; sh, short hairpin RNA.

determine whether DDAH2 was involved in myocardial fibrosis in diabetic rats. Following Masson staining, collagen fibers turned blue and normal cells were stained red. In the diabetic rats of the model, DDAH2-NC, shDDAH2-NC, and L-NNA + DDAH2 groups, the myocardial cells were arranged loosely and disorderly with hypertrophied and deformed cardiac muscle cells. In addition, collagen fibers were distributed densely in the myocardial cells and blood vessels. Compared with the diabetic rats of model group, the myocardial tissues in the diabetic rats of the DDAH2 group were arranged regularly with reduced swelling and collagen fibers, whereas the arrangement of myocardial cells in the diabetic rats of the shDDAH2 and L-NNA groups was disordered with aggravated swelling and increased collagen fibers (Fig. 3A).

Following H\&E staining, the myocardial cells in the diabetic rats of the model, DDAH2-NC, shDDAH2-NC, and L-NNA + DDAH2 groups were hypertrophied with obvious myocardial fiber damage and rupture. Less myocardial hypertrophy and necrosis, and generally complete cell morphology were observed in the DDAH2 group when compared with the model group. The diabetic rats in the shDDAH2 and L-NNA groups showed more hypertrophic and distorted myocardial cells, with disordered arrangement and an increase of intercellular space compared with the model group (Fig. 3B). These results showed DDAH2 attenuated myocardial fibrosis by reducing swelling and decreasing collagen fibers in diabetic rats.

DDAH2 inhibits migration of myocardial cells under high glucose conditions. Transwell, RT-qPCR and western blot assays were performed to evaluate the function of DDAH2 in the migration of $\mathrm{H} 9 \mathrm{C} 2$ myocardial cells under high glucose conditions. The results of the Transwell assay (Fig. 4A) showed that the migration ability of the $\mathrm{H} 9 \mathrm{C} 2$ cells in the DDAH2 group was significantly decreased compared with that in the model group $(\mathrm{P}<0.05)$, whereas the migration ability of $\mathrm{H} 9 \mathrm{C} 2$ cells in the shDDAH2 and L-NNA groups was significantly enhanced $(\mathrm{P}<0.05)$. No significant differences in $\mathrm{H} 9 \mathrm{C} 2$ cell migration were observed in the DDAH2-NC, shDDAH2-NC and L-NNA + DDAH2 groups $(\mathrm{P}>0.05)$.

In addition, the results of the RT-qPCR and western blot analyses (Fig. 4B and C) showed that, compared with the $\mathrm{H} 9 \mathrm{C} 2$ cells of the model group, the mRNA and protein levels of collagen I, MMP2 and TIMP2 in the H9C2 cells of the DDAH2 group were significantly decreased (all $\mathrm{P}<0.05$ ). The mRNA and protein levels of collagen I, MMP2 and TIMP2 in the $\mathrm{H} 9 \mathrm{C} 2$ cells of the shDDAH2 and L-NNA groups were significantly increased, compared with those in the $\mathrm{H} 9 \mathrm{C} 2$ cells of the model group (all $\mathrm{P}<0.05$ ). No noticeable differences in the mRNA and protein levels of collagen I, MMP2, and TIMP2 were found in the model, DDAH2-NC, shDDAH2-NC, and L-NNA + DDAH2 groups $(\mathrm{P}>0.05)$. These result indicated that DDAH2 negatively affected myocardial cell migration.

In addition, the results (Fig. 4D and E) showed that, compared with the $\mathrm{H} 9 \mathrm{C} 2$ cells in the model group, the $\mathrm{H} 9 \mathrm{C} 2$ cells in the DDAH2 group showed significantly decreased mRNA and protein expression levels of PRMT1 but increased mRNA and protein expression levels of DDAH2 (all $\mathrm{P}<0.05$ ). The H9C2 cells in the shDDAH2 and L-NNA groups exhibited increased mRNA and protein expression levels of PRMT1 but decreased mRNA and protein expression levels of DDAH2 compared with those in the model group (all $\mathrm{P}<0.05$ ). No significant differences in the mRNA and protein expression 
A
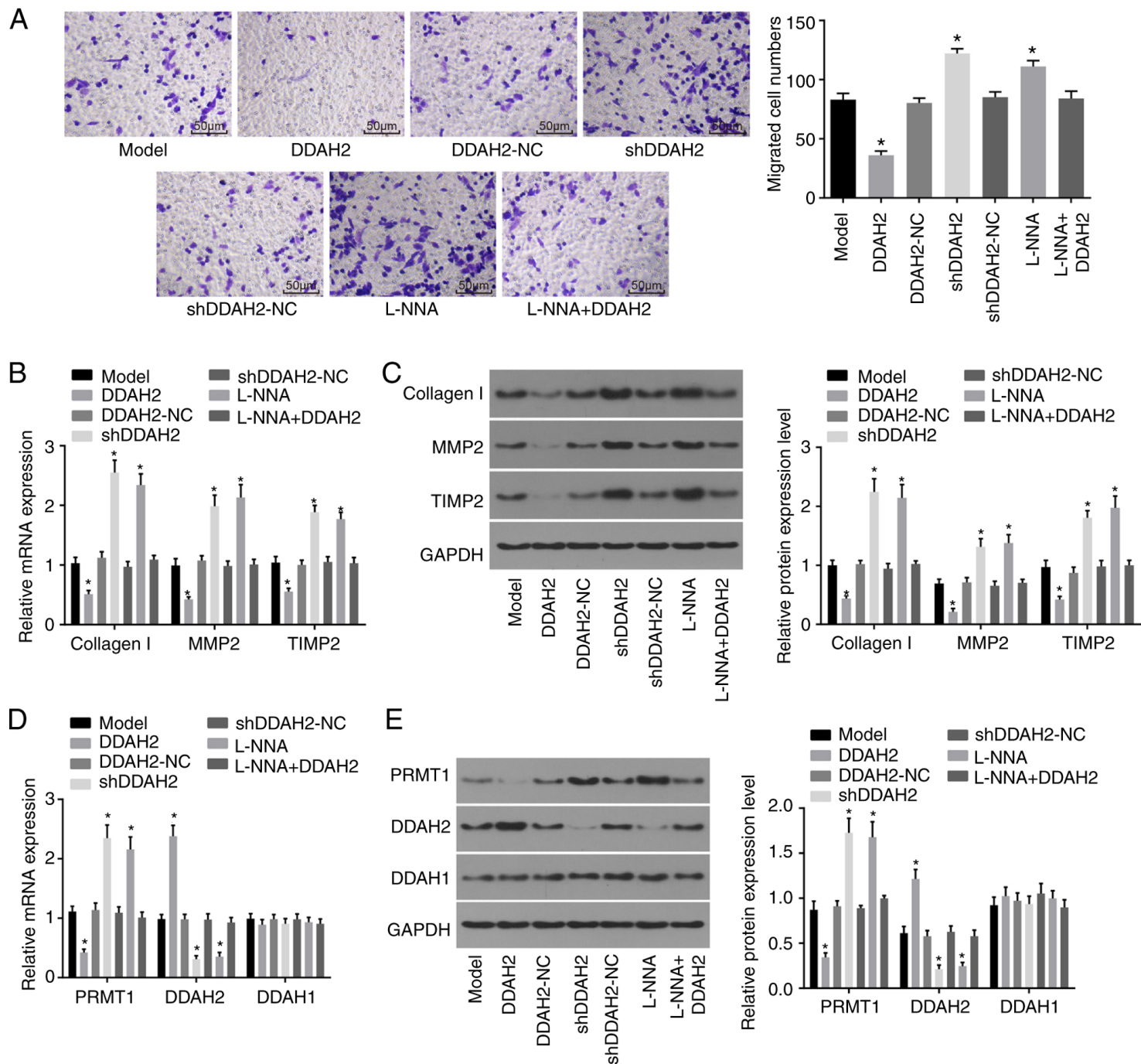

Figure 4. DDAH2 inhibits myocardial cell migration. (A) Migration ability of $\mathrm{H} 9 \mathrm{C} 2$ myocardial cells under high glucose conditions following $48 \mathrm{~h}$ of treatment with lentivirus expressing DDAH2 or shDDAH2, and/or L-NNA (magnification, x200). (B) mRNA levels of collagen I, MMP2 and TIMP in $\mathrm{H} 9 \mathrm{C} 2$ myocardial cells under high glucose conditions following $48 \mathrm{~h}$ of treatment with lentivirus expressing DDAH2 or shDDAH2, and/or L-NNA. (C) Protein levels of collagen I, MMP2 and TIMP in H9C2 myocardial cells under high glucose conditions following $48 \mathrm{~h}$ of treatment with lentivirus expressing DDAH2 or shDDAH2, and/or L-NNA. (D) mRNA expression of PRMT1, DDAH2 and DDAH1 in H9C2 myocardial cells under high glucose condition following $48 \mathrm{~h}$ of treatment with lentivirus expressing DDAH2 or shDDAH2, and/or L-NNA (E) Protein expression of PRMT1, DDAH2 and DDAH1 in H9C2 myocardial cells under high glucose conditions following $48 \mathrm{~h}$ of treatment with lentivirus expressing DDAH2 or shDDAH2, and/or L-NNA. Data are presented as the mean \pm standard deviation and analyzed by one-way analysis of variance. All data are representative of three independent experiments. " $\mathrm{P}<0.05$, vs. model group. DDAH, dimethylarginine dimethylaminohydrolase; PRMT1, protein arginine N-methyltransferase 1; NC, negative control; sh, short hairpin RNA; MMP2, matrix metalloproteinase 2; TIMP2, tissue inhibitor of metalloproteinase 2; GAPDH, glyceraldehyde-3-phosphate dehydrogenase.

levels of PRMT1 and DDAH2 were observed among the H9C2 cells in the model, DDAH2-NC, shDDAH2-NC and L-NNA+DDAH2 groups ( $\mathrm{P}>0.05)$. No significant differences in the mRNA and protein expression levels of DDAH1 were found among the groups $(\mathrm{P}>0.05)$. Taken together, these results suggested that DDAH2 may induce the activation of DDAH in myocardial cells (H9C2) under high glucose conditions.

DDAH2 activates the DDAH/ADMA/NOS/NO pathway in diabetic rats with myocardial fibrosis. Finally, the regulatory association between DDAH2 and the DDAH/ADMA/NOS/NO pathway was investigated in diabetic rats with myocardial fibrosis. Compared with the rats in the model group, the rats in the DDAH2 group exhibited lower serum ADMA content but higher serum DDAH activity, NOS activity and NO content (all $\mathrm{P}<0.05$ ); an opposite trend was observed in the shDDAH2 and L-NNA groups $($ all $\mathrm{P}<0.05)$. No notable differences in serum ADMA content, DDAH activity, NOS activity or NO content were observed among the model, DDAH2-NC, shDDAH2-NC, and L-NNA + DDAH2 groups ( $>0.05)$ (Fig. 5A-D).

The results of the RT-qPCR and western blot analyses (Fig. 5E and F) showed that, compared with the diabetic rats in the model group, the mRNA and protein levels of PRMT1 were decreased whereas those of DDAH2 were increased in the myocardial tissues of diabetic rats in the DDAH2 group (all $\mathrm{P}<0.05$ ). By contrast, the opposite trend was found in the shDDAH2 and L-NNA groups (all $\mathrm{P}<0.05$ ). No significant changes in the mRNA and protein levels of PRMT1 or DDAH2 were shown among the model, DDAH2-NC, shDDAH2-NC and L-NNA + DDAH2 groups $(\mathrm{P}>0.05)$. No significant 

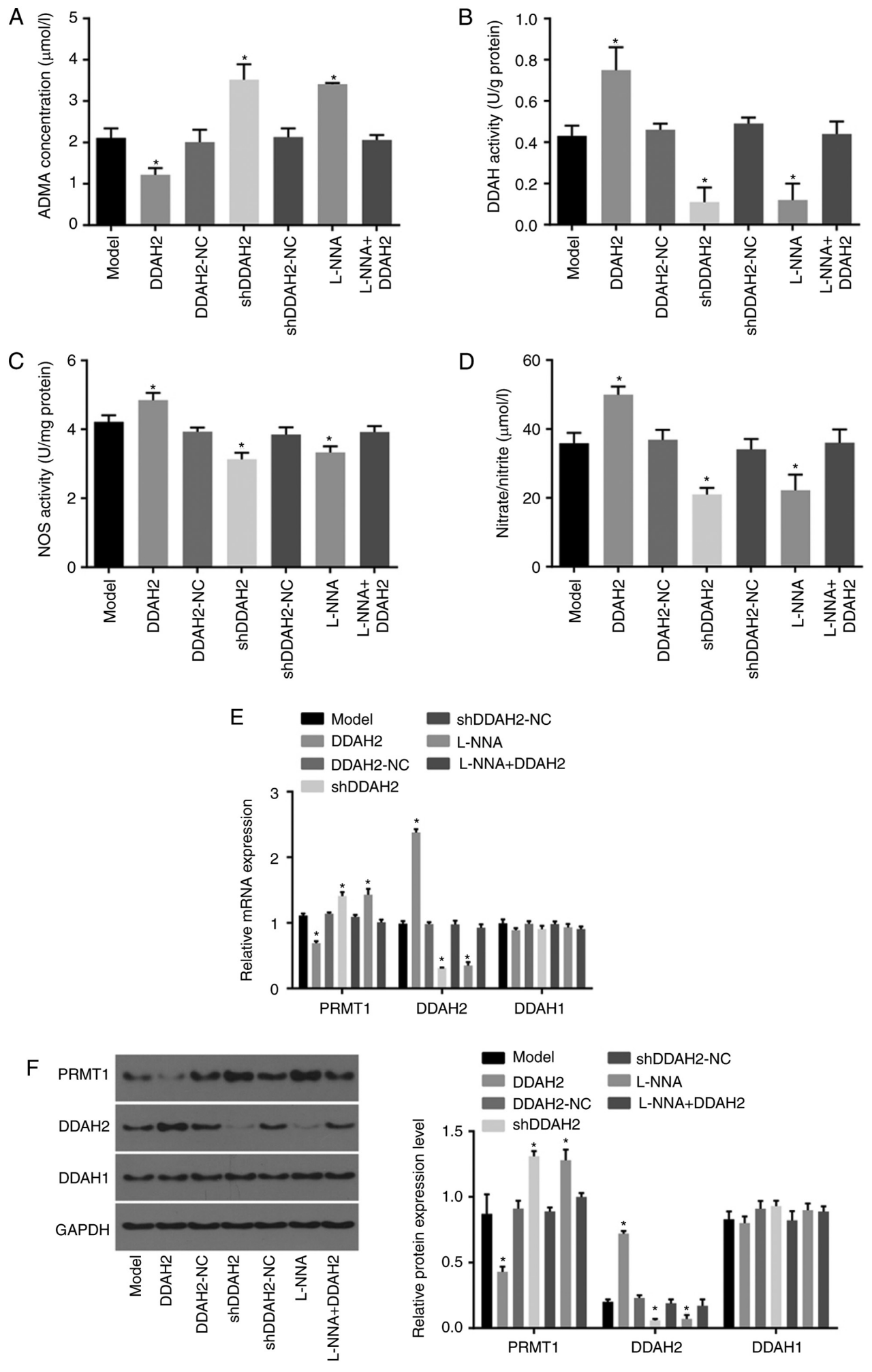

Figure 5. DDAH2 activates the DDAH/ADMA/NOS/NO pathway in diabetic rats with myocardial fibrosis. (A) Serum ADMA content in diabetic rats following 20 weeks of treatment with lentivirus expressing DDAH2 or shDDAH2, and/or L-NNA. (B) DDAH activity in myocardial tissues of diabetic rats following 20 weeks of treatment with lentivirus expressing DDAH2 or shDDAH2, and/or L-NNA. (C) NOS activity in myocardial tissues of diabetic rats following 20 weeks of treatment with lentivirus expressing DDAH2 or shDDAH2, and/or L-NNA. (D) NO content in myocardial tissues of diabetic rats following 20 weeks of treatment with lentivirus expressing DDAH2 or shDDAH2, and/or L-NNA. (E) mRNA and (F) protein levels of PRMT1, DDAH2 and DDAH1 in myocardial tissues of rats following 20 weeks of treatment with lentivirus expressing DDAH2 or shDDAH2, and/or L-NNA. Data are presented as the mean \pm standard deviation and were analyzed by one-way analysis of variance. "P $<0.05$, vs. model group All data are representative of three independent experiments. DDAH, dimethylarginine dimethylaminohydrolase; ADMA, asymmetric $\mathrm{N}^{\mathrm{G}}, \mathrm{N}^{\mathrm{G}}$ dimethyl-L-arginine; PRMT1, protein arginine $\mathrm{N}$-methyltransferase 1; NC, negative control; shRNA, short hairpin RNA; ADMA, asymmetric dimethylarginine; NOS, nitric oxide synthase; NO, nitric oxide; GAPDH, glyceraldehyde-3-phosphate dehydrogenase.

differences in the mRNA and protein levels of DDAH1 were observed among any groups $(\mathrm{P}>0.05)$. The above findings revealed that DDAH2 activated the DDAH/ADMA/NOS/NO pathway in diabetic rats with myocardial fibrosis. 


\section{Discussion}

DCM features molecular, metabolic and structural heart changes (22), and is considered to be the most common cause of high morbidity and mortality rates in diabetic patients (23). In an effort to identify a novel treatment method for DCM, the present study examined the mechanism underlying the effect of DDAH2 in DCM by regulating the DDAH/ADMA/NOS/NO pathway.

The first finding of the present study was that the DCM rats treated with DDAH2 exhibited reduced LVEDP, BG, TC, TG, FBG, FINS levels but increased LVSP and LV $\pm \mathrm{dp} / \mathrm{dt}$ levels in myocardial tissues, indicating that DDAH2 improved cardiac function in diabetic rats. The overexpression of DDAH has been reported to delay the development of graft coronary artery disease (24). DDAH is capable of altering key fibrotic signaling cascades and is considered a promising treatment for patients with idiopathic pulmonary fibrosis $(25,26)$. The sequence variation in DDAH1 and DDAH2 genes is reported to be implicated in type 2 diabetes (27-29). In line with the findings of the present study, a previous study indicated that the upregulation of DDAH2 improved endothelial dysfunction and can be regarded as a positive factor for diabetes treatment (30). The above findings indicate that DDAH2 is a positive factor for cardiac function in diabetes.

In addition, the present study showed that DDAH2 exerted inhibitory effects on myocardial cell migration under high glucose conditions and myocardial fibrosis in diabetic rats. This result is in accordance with higher expression levels of collagen I, MMP2 and TIMP2. Collagen is regarded as the major component of the extracellular matrix and mainly appears in the mammalian body (31). Former studies have reported that excessive synthesis of collagen can lead to myocardial fibrosis $(32,33)$. It was suggested in a previous study that MMP positively correlates with type I collagen (34). DDAH is a vital enzyme which may have a positive correlation with MMP-2 and collagen (35-37). MMPs constitute a group of zinc-binding proteolytic enzymes which commonly remodel the extracellular matrix and are involved in the inflammatory response. MMP-2, as one member of the MMP family, is closely associated with diabetes $(38,39)$. Furthermore, it has been revealed that MMP2 and MMP9 are implicated in the migration of human cardiomyocyte progenitor cells (40). TIMPs are endogenous inhibitors of MMPs and are involved in the common biological behaviors of cells (41). In addition, TIMP2 has been found to be responsible for enhancing the migration of epidermal keratinocytes and dermal fibroblasts (42), and myocardial fibrosis can be suppressed by the rosuvastatin-induced upregulation of DDAH2 (43). These results reveal that the migration of myocardial cells and myocardial fibrosis can be disrupted by DDAH2.

Of note, the present study found that DDAH2 positively regulates the DDAH/ADMA/NOS/NO pathway in myocardial cells under high glucose conditions and in diabetic rats with myocardial fibrosis, which resulted in a decrease in PRMT1 and ADMA content, together with increases in NOS activity and NO content. In detail, silencing or the overexpression of DDAH2 in diabetic rats showed effects on the expression of key factors associated with the DDAH/ADMA/NOS/NO pathway, aggravating or alleviating the myocardial fibrosis of diabetic rats. ADMA can be catabolized into citrulline and methylamines in an active manner under physiological conditions, and this effect is modulated by the alteration of DDAH (44). ADMA, which appears during the hydrolysis of methylated proteins, is produced by consistent protein turnover and catalyzed by S-adenosylmethionine PRMT-1 (45). PRMT-1 is downregulated by DDAH, and ADMA is negatively associated with DDAH $(46,47)$. In addition, DDAH is positively correlated with NOS and NO through an inverse association with ADM (48). Similar to the findings of the present study, several studies have suggested that ADMA is negatively associated with DDAH1, whereas NOS and NO are positively associated with DDAH1. In these regulatory processes, ADMA is a primary endogenous factor inhibiting the production of NOS and NO $(47,49,50)$. Previously, it has been indicated that a lower expression of ADMA is essential for reducing the cardiovascular risk in diabetic patients (51). The suppression of endothelial NOS has been revealed to enhance myocardial fibrosis (52). In addition, the expression of DDAH2 is decreased and that of ADMA is increased under high glucose conditions, and the high glucose-induced cell senescence and upregulated expression of ADMA may be promoted in the absence of DDAH2 (53). Taken together, it is possible to suggest a model in which DDAH2 affects diabetes-induced cardiac damage and myocardial fibrosis via modulation of the DDAH/ADMA/NOS/NO pathway.

In conclusion, the results of the present study suggest that the treatment of diabetic model rats with DDAH2 is able to improve impaired cardiac function and myocardial fibrosis, thus delaying the progression of DCM and inhibiting subsequent undesirable consequences. The DDAH/ADMA/NOS/NO pathway was stimulated by DDAH2 treatment, therefore, DDAH2 is considered to be a novel therapeutic approach specific to DCM. However, additional in vitro investigations are required to definitively identify the molecular mechanisms and target genes of DDAH2.

\section{Acknowledgements}

Not applicable.

\section{Funding}

The present study was supported by the Health Science and Technology Project of Yunnan Province (grant no. 2014NS243), the Applied Yunnan Local Colleges Basic Research Joint Special Key Projects in 2017 (grant no. 2017FH001-009) and the Basic Research Program of Science and Technology Plan of Yunnan Province [grant no. 2017FF117(-064)].

\section{Availability of data and materials}

The datasets used and/or analyzed during the current study are available from the corresponding author on reasonable request.

\section{Authors' contributions}

ZDZ JMY XMF and XCW contributed to conception and design of the study. JYY, XRW and PH contributed to acquisition, analysis, and interpretation of the data and was the major contributor in writing the manuscript. YQL WX and JLD each contributed to acquisition of the data, WYL, HF, ZHX and 
$\mathrm{XZ}$ collected the clinical specimen and carried out the animal experiments. ZDZ, JMY, XMF, XCW and XZ contributed to revision of the manuscript. JYY, XRW, PH, YQL and WX contributed to analysis and interpretation of the data and to revision of the manuscript. All authors read and approved the final manuscript.

\section{Ethics approval and consent to participate}

The study was approved by The First People's Hospital of Yunnan Province, Affiliated Hospital of Kunming Science and Technology University. All experimental procedures and protocols were in line with the recommendations of the Guide for the Care and Use of Laboratory Animals of the American National Institutes of Health.

\section{Patient consent for publication}

Not applicable.

\section{Competing interests}

The authors declare that they have no competing interests.

\section{References}

1. Nouhjah S, Shahbazian H, Amoori N, Jahanfar S, Shahbazian N, Jahanshahi A and Cheraghian B: Postpartum screening practices, progression to abnormal glucose tolerance and its related risk factors in Asian women with a known history of gestational diabetes: A systematic review and meta-analysis. Diabetes Metab Syndr 2(Suppl 11): S703-S712, 2017.

2. Han K, Yao J, Yin X, Zhao M and Sun Q: Review on the prevalence of diabetes and risk factors and situation of disease management in floating population in China. Glob Health Res Policy 2: 33, 2017.

3. Zhu WW, Yang HX, Wang C, Su RN, Feng H and Kapur A: High prevalence of gestational diabetes mellitus in beijing: Effect of maternal birth weight and other risk factors. Chin Med J (Engl) 130: 1019-1025, 2017.

4. Xu Y, Wang L, He J, Bi Y, Li M, Wang T, Wang L, Jiang Y, Dai M, Lu J, et al: Prevalence and control of diabetes in Chinese adults. JAMA 310: 948-959, 2013.

5. Liu F, Song R, Feng Y, Guo J, Chen Y, Zhang Y, Chen T, Wang Y, Huang Y, Li CY, et al: Upregulation of MG53 induces diabetic cardiomyopathy through transcriptional activation of peroxisome proliferation-activated receptor $\alpha$. Circulation 131: 795-804, 2015.

6. Berclaz PY, Gao H, Tobian JA, Swanson DL, Webb DM, Crapo RO and Jensen RL: The impact of diabetes and age on pulmonary function: Data from the National Health and Nutrition Examination Survey. Diabetes Res Clin Pract 83: e1-e3, 2009.

7. Jellis C, Martin J, Narula J and Marwick TH: Assessment of nonischemic myocardial fibrosis. J Am Coll Cardiol 56: 89-97, 2010.

8. Ares-Carrasco S, Picatoste B, Benito-Martin A, Zubiri I, Sanz AB, Sanchez-Nino MD, Ortiz A, Egido J, Tunon J and Lorenzo O: Myocardial fibrosis and apoptosis, but not inflammation, are present in long-term experimental diabetes. Am J Physiol Heart Circ Physiol 297: H2109-H2119, 2009.

9. Hollekim-Strand SM, Bjorgaas MR, Albrektsen G, Tjonna AE, Wisloff $U$ and Ingul CB: High-intensity interval exercise effectively improves cardiac function in patients with type 2 diabetes mellitus and diastolic dysfunction: A randomized controlled trial. J Am Coll Cardiol 64: 1758-1760, 2014.

10. Tappia PS, Thliveris J, Xu YJ, Aroutiounova N and Dhalla NS: Effects of amino acid supplementation on myocardial cell damage and cardiac function in diabetes. Exp Clin Cardiol 16: e17-e22, 2011.

11. Karamitsos TD: Vascular and myocardial fibrosis in diabetes mellitus. Cardiology 114: 105-106, 2009.
12. Lai YL, Aoyama S, Ohata M, Otsuka N, Shiokawa H, Tomono S, Fujiwara Y, Kanazawa H, Miyoshi N and Ohshima H: Dysregulation of dimethylargininedimethylaminohydrolase/asymmetric dimethylarginine pathway in rat type II diabetic nephropathy. J Clin Biochem Nutr 51: 143-149, 2012.

13. Sakurada M, Shichiri M, Imamura M, Azuma H and Hirata Y: Nitric oxide upregulates dimethylarginine dimethylaminohydrolase-2 via cyclic GMP induction in endothelial cells. Hypertension 52: 903-909, 2008.

14. Torondel B, Nandi M, Kelly P, Wojciak-Stothard B, Fleming I and Leiper J: Adenoviral-mediated overexpression of DDAH improves vascular tone regulation. Vasc Med 15: 205-213, 2010.

15. Zheng J, Wang K, Jin P, Dong C, Yuan Q, Li Y and Yang Z: The association of adipose-derived dimethylarginine dimethylaminohydrolase-2 with insulin sensitivity in experimental type 2 diabetes mellitus. Acta Biochim Biophys Sin (Shanghai) 45: 641-648, 2013.

16. Thum T, Fraccarollo D, Schultheiss M, Froese S, Galuppo P, Widder JD, Tsikas D, Ertl G and Bauersachs J: Endothelial nitric oxide synthase uncoupling impairs endothelial progenitor cell mobilization and function in diabetes. Diabetes 56: 666-674, 2007.

17. Chen D, Zhang KQ, Li B, Sun DQ, Zhang H and Fu Q: Epigallocatechin-3-gallate ameliorates erectile function in aged rats via regulation of PRMT1/DDAH/ADMA/NOS metabolism pathway. Asian J Androl 19: 291-297, 2017.

18. Wang JH, Chen D, Zhang KQ, Zhang $\mathrm{H}$ and Fu Q: Effect of DDAH/ADMA/NOS regulation pathway on cavernae corporum cavernosorum rat penis of different age. Andrologia 48: 262-267, 2016.

19. Yuan Q, Hu CP, Gong ZC, Bai YP, Liu SY, Li YJ and Jiang JL: Accelerated onset of senescence of endothelial progenitor cells in patients with type 2 diabetes mellitus: Role of dimethylarginine dimethylaminohydrolase 2 and asymmetric dimethylarginine. Biochem Biophys Res Commun 458: 869-876, 2015.

20. Lu CW, Lin Y, Lei YP, Wang L, He ZM and Xiong Y: Pyrrolidine dithiocarbamate ameliorates endothelial dysfunction in thoracic aorta of diabetic rats by preserving vascular DDAH activity. PLoS One 12: e0179908, 2017.

21. Ayuk SM, Abrahamse H and Houreld NN: The role of photobiomodulation on gene expression of cell adhesion molecules in diabetic wounded fibroblasts in vitro. J Photochem Photobiol B 161: 368-374, 2016.

22. Mizamtsidi M, Paschou SA, Grapsa J and Vryonidou A: Diabetic cardiomyopathy: A clinical entity or a cluster of molecular heart changes? Eur J Clin Invest 46: 947-953, 2016.

23. Tang SG, Liu XY, Ye JM, Hu TT, Yang YY, Han T and Tan W: Isosteviol ameliorates diabetic cardiomyopathy in rats by inhibiting ERK and NF- $\kappa$ B signaling pathways. J Endocrinol 238: 47-60, 2018.

24. Tanaka M, Sydow K, Gunawan F, Jacobi J, Tsao PS, Robbins RC and Cooke JP: Dimethylarginine dimethylaminohydrolase overexpression suppresses graft coronary artery disease. Circulation 112: 1549-1556, 2005.

25. Janssen W, Pullamsetti SS, Cooke J, Weissmann N, Guenther A and Schermuly RT: The role of dimethylarginine dimethylaminohydrolase (DDAH) in pulmonary fibrosis. J Pathol 229: 242-249, 2013.

26. Pullamsetti SS, Savai R, Dumitrascu R, Dahal BK, Wilhelm J, Konigshoff M, Zakrzewicz D, Ghofrani HA, Weissmann N, Eickelberg O, et al: The role of dimethylarginine dimethylaminohydrolase in idiopathic pulmonary fibrosis. Sci Transl Med 3: 87ra53, 2011.

27. Abhary S, Burdon KP, Kuot A, Javadiyan S, Whiting MJ, Kasmeridis N, Petrovsky N and Craig JE: Sequence variation in DDAH1 and DDAH2 genes is strongly and additively associated with serum ADMA concentrations in individuals with type 2 diabetes. PLoS One 5: e9462, 2010.

28. Seo HA, Kim SW, Jeon EJ, Jeong JY, Moon SS, Lee WK, Kim JG, Lee IK and Park KG: Association of the DDAH2 gene polymorphism with type 2 diabetes and hypertension. Diabetes Res Clin Pract 98: 125-131, 2012.

29. Lu TM, Lin SJ, Lin MW, Hsu CP and Chung MY: The association of dimethylarginine dimethylaminohydrolase 1 gene polymorphism with type 2 diabetes: A cohort study. Cardiovasc Diabetol 10: 16, 2011.

30. Lu CW, Guo Z, Feng M, Wu ZZ, He ZM and Xiong Y: Ex vivo gene transferring of human dimethylarginine dimethylaminohydrolase-2 improved endothelial dysfunction in diabetic rat aortas and high glucose-treated endothelial cells. Atherosclerosis 209: 66-73, 2010 . 
31. Rajan N, Habermehl J, Coté MF, Doillon CJ and Mantovani D: Preparation of ready-to-use, storable and reconstituted type I collagen from rat tail tendon for tissue engineering applications. Nat Protoc 1: 2753-2758, 2006

32. Challa AA, Vukmirovic M, Blackmon J and Stefanovic B: Withaferin-A reduces type I collagen expression in vitro and inhibits development of myocardial fibrosis in vivo. PLoS One 7: e42989, 2012.

33. Querejeta R, López B, González A, Sánchez E, Larman M, Martínez Ubago JL and Díez J: Increased collagen type I synthesis in patients with heart failure of hypertensive origin: Relation to myocardial fibrosis. Circulation 110: 1263-1268, 2004.

34. Yucel T, Mutnal A, Fay K, Fligiel SE, Wang T, Johnson T, Baker SR and Varani J: Matrix metalloproteinase expression in basal cell carcinoma: Relationship between enzyme profile and collagen fragmentation pattern. Exp Mol Pathol 79: 151-160, 2005 .

35. Hu X, Atzler D, Xu X, Zhang P, Guo H, Lu Z, Fassett J, Schwedhelm E, Böger RH, Bache RJ and Chen Y: Dimethylarginine dimethylaminohydrolase-1 is the critical enzyme for degrading the cardiovascular risk factor asymmetrical dimethylarginine. Arterioscler Thromb Vasc Biol 31 1540-1546, 2011.

36. $\mathrm{Ko} \mathrm{CH}$, Shen SC, Lee TJ and Chen YC: Myricetin inhibits matrix metalloproteinase 2 protein expression and enzyme activity in colorectal carcinoma cells. Mol Cancer Ther 4: 281-290, 2005.

37. Hasegawa K, Wakino S, Tanaka T, Kimoto M, Tatematsu S, Kanda T, Yoshioka K, Homma K, Sugano N, Kurabayashi M, et al: Dimethylarginine dimethylaminohydrolase 2 increases vascular endothelial growth factor expression through $\mathrm{Sp1}$ transcription factor in endothelial cells. Arterioscler Thromb Vasc Biol 26: 1488-1494, 2006.

38. Lewandowski KC, Banach E, Bieńkiewicz M and Lewiński A: Matrix metalloproteinases in type 2 diabetes and non-diabetic controls: Effects of short-term and chronic hyperglycaemia. Arch Med Sci 7: 294-303, 2011.

39. Van Linthout S, Seeland U, Riad A, Eckhardt O, Hohl M, Dhayat N, Richter U, Fischer JW, Böhm M, Pauschinger M, et al: Reduced MMP-2 activity contributes to cardiac fibrosis in experimental diabetic cardiomyopathy. Basic Res Cardiol 103: 319-327, 2008

40. Liu J, van Mil A, Aguor EN, Siddiqi S, Vrijsen K, Jaksani S, Metz C, Zhao J, Strijkers GJ, Doevendans PA and Sluijter JP: MiR-155 inhibits cell migration of human cardiomyocyte progenitor cells (hCMPCs) via targeting of MMP-16. J Cell Mol Med 16: 2379-2386, 2012.

41. Peterson NB, Beeghly-Fadiel A, Gao YT, Long J, Cai Q, Shu XO and Zheng W: Polymorphisms in tissue inhibitors of metalloproteinases- 2 and -3 and breast cancer susceptibility and survival. Int J Cancer 125: 844-850, 2009.

42. Miyoshi H, Kanekura T, Aoki T and Kanzaki T: Beneficial effects of tissue inhibitor of metalloproteinases-2 (TIMP-2) on chronic dermatitis. J Dermatol 32: 346-353, 2005.
43. Zhou R, Ma P, Xiong A, Xu Y, Wang Y and Xu Q: Protective effects of low-dose rosuvastatin on isoproterenol-induced chronic heart failure in rats by regulation of DDAH-ADMA-NO pathway. Cardiovasc Ther 35: 2017.

44. Frombaum M, Therond P, Djelidi R, Beaudeux JL, Bonnefont-Rousselot D and Borderie D: Piceatannol is more effective than resveratrol in restoring endothelial cell dimethylarginine dimethylaminohydrolase expression and activity after high-glucose oxidative stress. Free Radic Res 45: 293-302, 2011.

45. Novella S, Laguna-Fernández A, Lázaro-Franco M, Sobrino A, Bueno-Betí C, Tarín JJ, Monsalve E, Sanchís J and Hermenegildo C: Estradiol, acting through estrogen receptor alpha, restores dimethylarginine dimethylaminohydrolase activity and nitric oxide production in oxLDL-treated human arterial endothelial cells. Mol Cell Endocrinol 365: 11-16, 2013.

46. Pope AJ, Karuppiah K and Cardounel AJ: Role of the PRMT-DDAH-ADMA axis in the regulation of endothelial nitric oxide production. Pharmacol Res 60: 461-465, 2009.

47. Jiang DJ, Jia SJ, Yan J, Zhou Z, Yuan Q and Li YJ: Involvement of DDAH/ADMA/NOS pathway in nicotine-induced endothelial dysfunction. Biochem Biophys Res Commun 349: 683-693, 2006.

48. Palm F, Onozato ML, Luo Z and Wilcox CS: Dimethylarginine dimethylaminohydrolase (DDAH): Expression, regulation, and function in the cardiovascular and renal systems. Am J Physiol Heart Circ Physiol 293: H3227-H3245, 2007.

49. Jiang DJ, Jia SJ, Dai Z and Li YJ: Asymmetric dimethylarginine induces apoptosis via p38 MAPK/caspase-3-dependent signaling pathway in endothelial cells. J Mol Cell Cardiol 40: 529-539, 2006.

50. Greco R, Ferrigno A, Demartini C, Zanaboni A, Mangione AS, Blandini F, Nappi G, Vairetti M and Tassorelli C: Evaluation of ADMA-DDAH-NOS axis in specific brain areas following nitroglycerin administration: Study in an animal model of migraine. J Headache Pain 16: 560, 2015.

51. King DE, Player M and Everett CJ: The impact of pioglitazone on ADMA and oxidative stress markers in patients with type 2 diabetes. Prim Care Diabetes 6: 157-161, 2012.

52. Kazakov A, Hall R, Jagoda P, Bachelier K, Müller-Best P, Semenov A, Lammert F, Böhm M and Laufs U: Inhibition of endothelial nitric oxide synthase induces and enhances myocardial fibrosis. Cardiovasc Res 100: 211-221, 2013.

53. Yuan Q, Peng J, Liu SY, Wang CJ, Xiang DX, Xiong XM, $\mathrm{Hu} \mathrm{CP}$ and $\mathrm{Li} \mathrm{YJ}$ : Inhibitory effect of resveratrol derivative BTM-0512 on high glucose-induced cell senescence involves dimethylaminohydrolase/asymmetric dimethylarginine pathway. Clin Exp Pharmacol Physiol 37:630-635, 2010.

This work is licensed under a Creative Commons Attribution-NonCommercial-NoDerivatives 4.0 International (CC BY-NC-ND 4.0) License. 